\title{
Correlative Petrographic and Spectroscopic Characterization of Boquillas Shale Samples Before and After Hydrous Pyrolysis: Understanding Diagenesis and Thermogenesis as it Relates to Storage and Expulsion
}

Adam R. Boehlke ${ }^{1}$, Javin Hatcherian², Paul C. Hackley², Justin E. Birdwell ${ }^{1}$, Aaron M. Jubb ${ }^{2}$, and Brett J. Valentine ${ }^{2}$

1. Central Energy Resources Science Center, U.S. Geological Survey, Denver, CO, USA.

2. Eastern Energy Resources Science Center, U.S. Geological Survey, Reston, VA, USA.

* Corresponding author: aboehlke@usgs.gov

To better understand self-sourced petroleum systems like the Late Cretaceous Eagle Ford Shale, the microscale diagenetic processes that lead to formation of indigenous shale oil resources must be understood inorder to assess macro-scale phenomena related to production [1].

Self-sourced petroleum systems are unique in that the source rock is also where generated products are stored. In this study, a sample of low maturity (Ro $\sim 0.5 \%$ ) Boquillas Shale collected from a roadcut near Del Rio, Texas was imaged both before and after hydrous pyrolysis (HP) at 300 and $330{ }^{\circ} \mathrm{C}$ for 72 hours using optical microscopy (reflectance), field emission scanning electron microscopy along with micro-Raman spectroscopic methods [2-7]. This allowed for examination of micro-scale changes in mineral matrix, organic matter composition and porosity related to different degrees of thermal stress.

Imaged areas were position registered to allow for direct comparison of results generated by the different characterization tools. Multiple maceral types, including vitrinite, liptinite, inertinite, solid bitumen, and micrinite were detected and characterized petrographically by both optical and electron microscopy techniques to better understand how textural and mineral alteration relate to diagenesis and thermogenesis in the source rock [Figs. A-B]. Changes in maceral types after HP showed shifts in spectral properties with increasing temperature consistent with previously observed effects of increased thermal stress [1,2]. These changes included increases in reflectance, shifts in fluorescence wavelengths (yellow to orange) and changes in Raman parameters based on $\mathrm{D}$ and $\mathrm{G}$ bands that indicate increased aromaticity [5,6,7]. The nature of production from the Eagle Ford Shale (source rock being the production target) indicates that the usual processes of petroleum expulsion and migration from the source rock is mitigated, possibly by intrinsic micro-scale diagenesis and thermogenesis processes that accommodate a volume change during conversion of solid organic matter to petroleum fluids. These micro-scale changes in the organic and mineral components during thermal maturation may aid in accommodation of generated fluids while maintaining limited permeability. Alteration products resulting from HP will be discussed as well as similarities and differences between artificially matured and geologically mature rock matrices.

\section{References:}

[1] Boehlke, A.R. and Birdwell, J.E., 2017 Mountjoy Carbonate Research Conference, June 26-30, 2017, Austin, TX (2017)

[2] Hackley, P.C., et al., AAPG Hedberg Conference Program Abstracts, Houston, TX (2019), p. 125.

[3] Hackley, P.C., et al., Journal of Microscopy 267(3) (2017), p. 371.

[4] Hackley, P.C., et al., Microscopy and Microanalysis 23 (2017), p. 2112.

[5] Jubb, A.M, et al., International Journal of Coal Geology 199 (2018), p. 1.

[6] Valentine, B.J., and Hackley, P.C., AAPG Memoir 121: Mudstone Diagenesis: Research Perspectives for Shale Hydrocarbon reservoirs, Seals, and Source Rocks. (in press) 
[7] Valentine, B.J. and Hackley, P.C. Society for Organic Petrology Annual Meeting, Joint Meeting of TSOP-AASP-ICCP. Houston, Texas (2016).
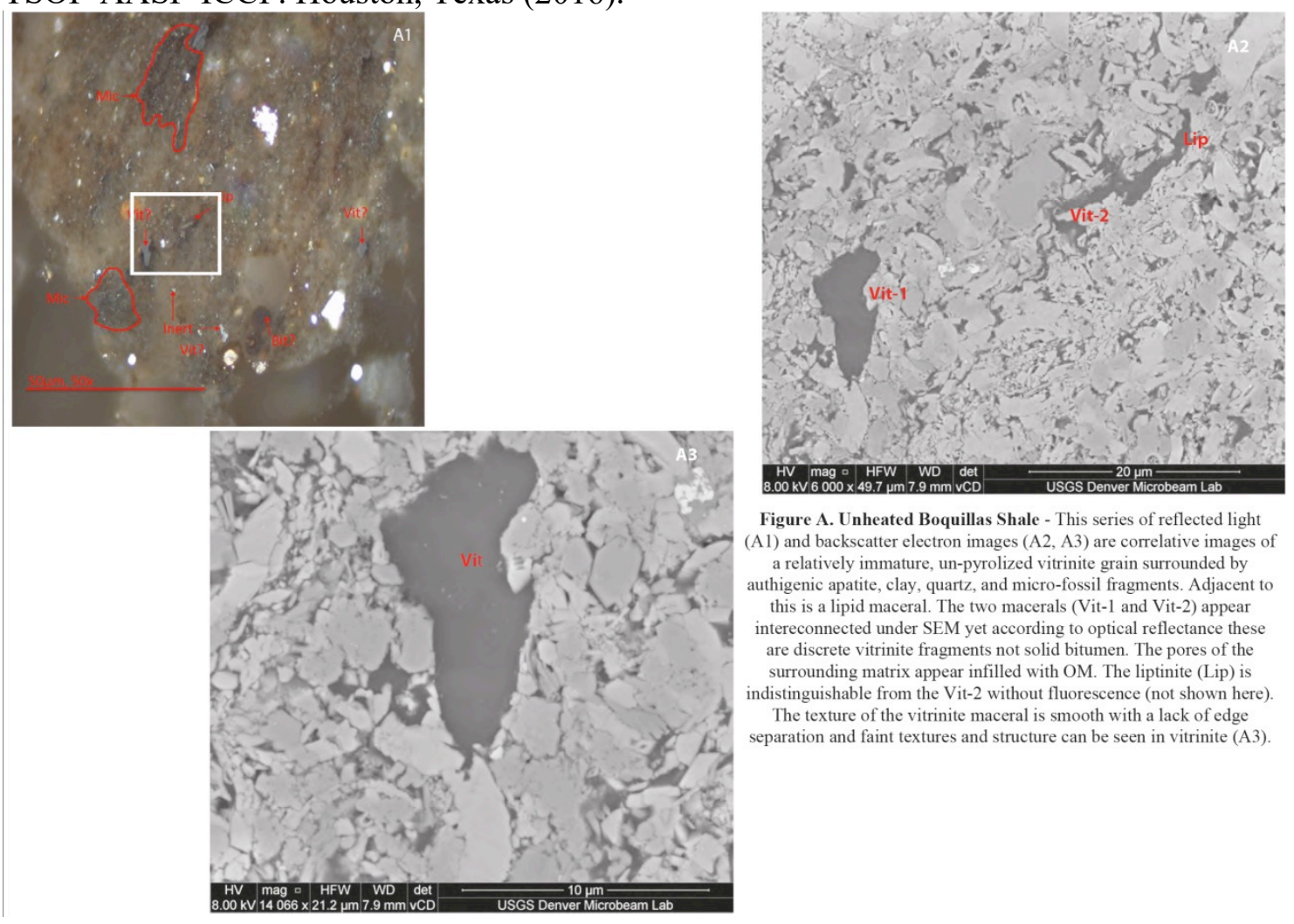

Figure A. Unheated Boquillas Shale - This series of reflected light

(A1) and backscatter electron images (A2, A3) are correlative images of a relatively immature, un-pyrolized vitrinite grain surrounded by authigenic apatite, clay, quartz, and micro-fossil fragments. Adjacent to this is a lipid maceral. The two macerals (Vit-1 and Vit-2) appear intereconnected under SEM yet according to optical reflectance these are discrete vitrinite fragments not solid bitumen. The pores of the surrounding matrix appear infilled with OM. The liptinite (Lip) is indistinguishable from the Vit-2 without fluorescence (not shown here) The texture of the vitrinite maceral is smooth with a lack of edge separation and faint textures and structure can be seen in vitrinite (A3).
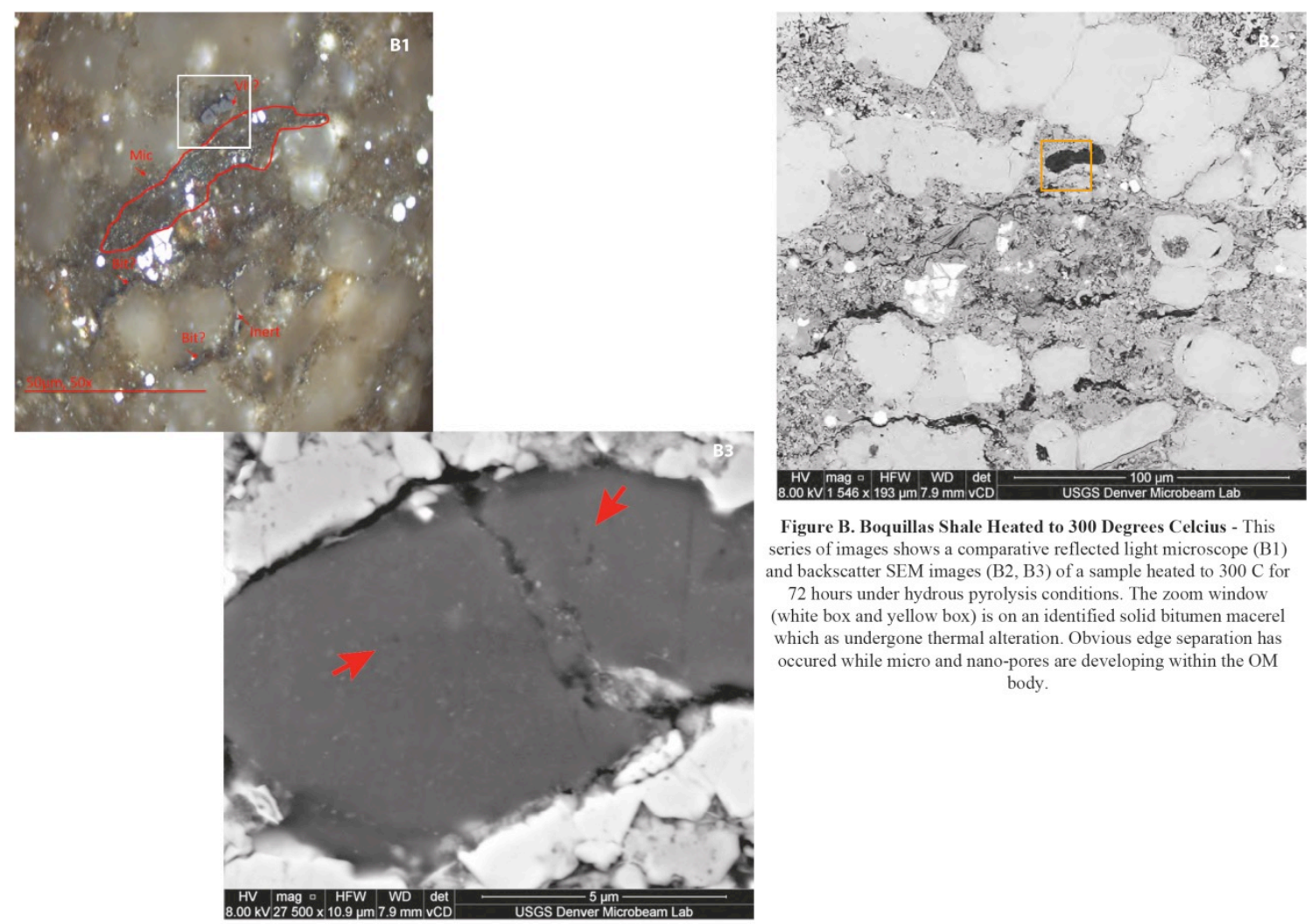

Figure B. Boquillas Shale Heated to 300 Degrees Celcius - This series of images shows a comparative reflected light microscope (B1) and backscatter SEM images (B2, B3) of a sample heated to $300 \mathrm{C}$ for 72 hours under hydrous pyrolysis conditions. The zoom window

(white box and yellow box) is on an identified solid bitumen macerel which as undergone thermal alteration. Obvious edge separation has occured while micro and nano-pores are developing within the $\mathrm{OM}$ body. 